\title{
Crafting the Future of Computing Education in CC2020: A Workshop
}

\section{Dr. Stephen T Frezza, Gannon University}

Deacon Steve Frezza, PSEM is a professor of Software Engineering and chair of the Computer and Information Science department at Gannon University in Erie, PA. His research interests include Global Software Engineering, Affective Domain Learning, Engineering Education Research, as well as Philosophy of Engineering and Engineering Education. He is regularly involved in supporting the regional entrepreneurial ecosystem, as well as projects that serve the regional community. He is an active member and volunteer for both the Institute of Electrical and Electronic Engineers (IEEE) Computer Society and the American Society for Engineering Education (ASEE). He has published numerous conference papers and journal articles on innovations in Software Engineering curriculum development and Philosophy of Engineering \& Computing.

\section{Prof. Arnold Neville Pears, Uppsala University}

Arnold Pears received his BSc(Hons) in 1986 and PhD in 1994, both from La Trobe University, Melbourne, Australia. He occupied positions as lecturer and senior lecturer at La Trobe University between 1991 and 1998. In 1999 he was appointed as senior lecturer at Uppsala University, Sweden. He was awarded the Uppsala University Pedagogy Prize in 2008, and appointed as Associate Professor of Computing Education Research in May 2011. Roles at Uppsala University include appointment to the University Academic Senate, Programme Director for the IT Engineering programme, member of the selection committee for the Uppsala University Pedgogy prize and as member of the educational advisory board of the Faculty of Technology and Natural Sciences.

He has a strong interest in teaching and learning research in computer science and engineering, and leads the UpCERG research group in computing and engineering education research at Uppsala University. He has published more than 40 articles in the area internationally, and is well known as a computing education researcher through his professional activities in the ACM, and IEEE. In the IEEE he serves as a member of the Board of Governors of the IEEE Computer Society, where he is active in the Education Activities Board, serving also on the steering committee of the Frontiers in Education Conference and as Chair of the newly established Special Technical Community (STC) for Education. In addition he is a Director of CeTUSS (The Swedish National Center for Pedagogical Development of Technology Education in a Societal and Student Oriented Context, www.cetuss.se) and the IEEE Education Society Nordic Chapter. He as a reviewer for a number of major journals and conferences, including the Computer Science Education Journal (Taylor and Francis), the ACM SIGCSE and ITiCSE and Koli Calling International Computer Science Education conferences.

\section{Dr. Marisa Exter, Purdue University, West Lafayette (College of Engineering)}

Marisa Exter is an Assistant Professor of Learning Design and Technology in the College of Education at Purdue University. She holds a BS and MS in Computer Science, and has served as software developer, designer, and project manager both in industry and higher education.

Dr. Exter's research aims to provide recommendations to improve or enhance university-level design and technology programs (such as Computer Science, Engineering, Technology, and Instructional Design). Some of her previous research has focused on software designers' on-the-job skills and knowledge, their formal and non-formal educational experiences, and use of precedent materials. These studies have highlighted the importance of cross-disciplinary skills and student engagement in large-scale, real-world projects.

Dr. Exter currently leads an effort to evaluate a new multidisciplinary degree program which provides both liberal arts and technical content through competency-based experiential learning.

\section{Dr. Barry M. Lunt, Brigham Young University}




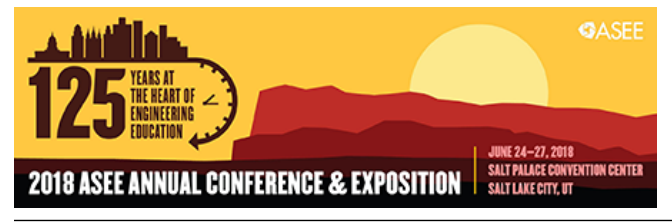

Dr. Barry Lunt has taught electronics engineering technology and information technology at Brigham Young University since 1993 where he now serves as full professor and Director of the School of Technology. He has also taught electronics at Utah State University and Snow College. Prior to his work in academics he worked for seven years as a design engineer for IBM in Tucson, AZ. He has consulted for several companies and has worked summer internships for Bell Labs (now Lucent Technologies), Larson - Davis (Utah), IBM (Vermont), and Micron Technologies (Utah and Idaho). His research areas are permanent digital data storage and engineering/computing education. Dr. Lunt is the author of "Electronic Physical Design" (Pearson Prentice Hall, 2004) and "The Marvels of Modern Electronics" (Dover, 2013) and has produced more than 70 peer-reviewed publications in the areas of electronic physical design, engineering education, and permanent data storage. He has seven U.S. patents and 20 more applied for. He was the chair of the committee that wrote the IT 2008 Model Curriculum, and a member of the task force that wrote the IT 2017 Model Curriculum. He was a member of the task force that wrote the CC2005 document, and is a member of the task force working on the 2020 update to that document. 


\section{Crafting the Future of Computing Education in CC2020: A Workshop}

Abstract-A consortium of national and international computing and engineering organizations are currently developing a new set of curricular resources titled 'Computing Curricula 2020' (CC2020). This project, based on its predecessor CC2005, aims to reflect the state-of-the-art in computing education and practice as well as provide insights into the future of the computing educational field for the 2020's and beyond.

This workshop provides an overview of the CC2005 and related reports and links them to the transition into the CC2020 project. It also provides participants with a unique opportunity to collaborate with members of the CC2020 task force and contribute to the development of the resources the project will deliver. The workshop authors and participants will engage in activities to help define how Computing is defined within the project and discuss how to extend its influence in global undergraduate computing education for the future. The authors anticipate full audience involvement and participation in formulating this vision.

Keywords-Computing education, CC2020, CC2005, future Computing education

\section{INTRODUCTION}

In 2015, the Association for Computing Machinery (ACM) began to explore avenues through which to update the broadly influential: Computing Curricula 2005 document, tagged as CC2005 [1]. ACM, the Association for Information Systems (AIS), and the IEEE Computer Society (IEEE-CS) were sponsors of the 2005 document. In 2016, ACM decided to proceed with the new project. It established an exploratory committee to ascertain the need for a new report.

ACM and IEEE-CS became the principal sponsors of the CC2020 project. Other professional organizations have joined in the effort with additional sponsorship; these include the Association for Information Systems (AIS), and Association for Information Technology Professionals, Education Special Interest Group (AITP/EDSIG). Project collaborators include Special Interest Group for Computer Human Interaction (SIGCHI), Information Processing Society of Japan (IPSJ), Information-Technology Promotion Agency (IPA) of Japan, the Chinese Computing Federation (CCF), the Conferencia Latinoamericana de Informática (CLEI) "LatinAmerican Conference on Informatics," and Computer Society of India (CSI). CC2020 supports a task force of thirty professionals from academia and industry from around the world. A subset of this task force is a steering committee of fifteen members. Currently, the task force represents fourteen countries and six continents. Funding is now in place and the project is moving forward with zest and determination. 


\section{PROJECT PURPOSE, GOAL, FOCUS, AND OUTCOME}

Computing Curricula 2020 is a joint project launched by professional computing societies to examine the current state of curricular guidelines for academic programs granting undergraduate degrees in computing. It provides a vision for the future of computing and resources for designing and evaluating curricula and content. The team of this international project represents organizations from academia, industry, and government.

\section{A. Project Goal}

The goal of the initiative is to produce a series of resources, among them a comprehensive report that compares and contrasts curricular guidelines to situate and contextualize them in the landscape of computing education. Ultimately, the project strives to help programs to prepare graduates both academically and professionally to meet the challenges of the 2020's.

\section{B. Project Focus}

The situation and context of degree granting computing programs are influenced by geography, varied conceptions of computing as disciplines, as professions, and as cultures. Geographically and culturally the project considers regions of the world by involving organizational representatives from a variety of countries. While currently published curricular guidelines (i.e., computer engineering, computer science, information systems, information technology, software engineering) and the currently emerging curricular models (i.e., cybersecurity, data science) comprise CC2020's central domain of interest, the CC2020 deliverables are intended to inform the prospects for rethinking existing or shaping new computing degree programs and disciplines.

\section{Project Outcome}

The objective of the CC2020 task force is to produce a comprehensive resource to inform academia, industry, governments, and students on the status and future of computing programs. The task force plans to prepare a comparative analysis of computing disciplines as represented in current curricular guidelines. It also plans to provide an integrative perspective of the disciplines within the computing landscape as well as illustrating shared and distinctive characteristics of discipline specific computing programs. Ultimately, the project plans to contribute to a vision of the future of computing. The project intends to develop interactive tools for academia and industry to prototype models of knowledge and skill development useful for exploring future curricular opportunities.

\section{WORKSHOP PLAN}

This workshop informs participants on the goals of the CC2020 project and gives them an opportunity to contribute to the project structure and resources.

\section{A. Workshop Structure}

The workshop organizers will present a high-level summary of the CC2005 report 
and summarize the aspirations of the CC2020 project. They will initiate an exploration of ways the Computing education community becomes a viable contributor to the pending CC2020 resources. The organizers expect lively audience input and viewpoints through small group discussions and vigorous dialogue among the participants. They expect to hear broad perspectives on future of Computing curricular developments and the role of Computing within other disciplines.

\section{B. Workshop Goal}

The salient goal of the workshop is to solicit participant input in defining sets of graduate attributes and competences which reflect a strong Computing education contribution to the learning outcomes and structure of the guidance for educators which will provide professional input to the content in the finalCC2020 report. In that manner, Computing will have a prominent presence in the future of computing education.

\section{WORKSHOP PRESENTERS}

The workshop presenters, together with their brief backgrounds, are as follows.

Marisa Exter (Purdue University) is a member of the CC2020 Task Force, Assistant Professor of Learning Design and Technology and a Faculty Fellow for Purdue Polytech's Transdisciplinary Studies in Technology program. She brings significant experience relating professionals' experience in computing to computing education [8].

Stephen T. Frezza (Gannon University) is a steering committee member of the CC2020 project. He has experience in building computing programs using the CC2005 and SE2004 Computing curricular reports [2], and has several publications on the relationship of the SE2004 and ABET accreditation. He is a professor of Software Engineering with research interests in affective domain education and philosophy of engineering and computing.

Barry Lunt (Brigham Young University) is a member of the CC2020 task force, Professor of Information Technology and Director of the School of Technology with over 31 years of experience. He is one of the original founders of SIGITE (ACM Special Interest Group for Information Technology Education) in 2003. He was the chair of the committee that produced the IT 2008 Model Curriculum [3], and a member of the IT 2017 task force which has produced the recent update [7].

Arnold Pears (KTH Royal Institute of Technology) is a member of the CC2020 Steering Committee, and Professor of Technical Science Education, School of Industrial Technology and Management at KTH Royal Institute of Technology Sweden. A past board member for the IEEE Computer Society (CS) and current IEEE Education Society Board member. He leads the IEEE CS's Special Technical Committee for Education. 


\section{FORMAT AND AUDIENCE}

Because the CC2020 project is emerging, there should be many diverse opinions on the content of the related report. This workshop provides a forum for vigorous discussion and opinion. Hence, a venue for diverse views on the subject and audience participation is essential and most welcome. This 90-minute workshop plans to engage Computing educators and practitioners so they provide suggestions that could be part of the pending CC2020 report.

\section{ACKNOWLEDGMENT}

The workshop presenters thank their affiliate institutions and organizations in making this workshop possible. They also thank the workshop participants for their time and contributions to the overall CC2020 effort.

\section{REFERENCES}

[1] ACM, et al., Computing Curricula 2005: The Overview Report covering undergraduate degree programs in Computer Engineering, Computer Science, Information Systems, Information Technology, and Computing (CC2005). http://www.acm.org/education/education/curric vols/CC2005-March06Final.pdf. Accessed 2017 August 30.

[2] IEEE et al., Computing 2004: Curriculum Guidelines for Undergraduate Degree Programs in Computing (SE2004); http://sites.computer.org/ccse/SE2004Volume.pdf. Accessed 2017 August 30.

[3] ACM et al., Information Technology 2008: Curriculum Guidelines for Undergraduate Degree Programs in Information Technology (IT2008); http://www.acm.org//education/curricula/IT2008\%20Curriculum.pdf. IT2008. Accessed 2017 August 30.

[4] ACM et al,. Computer Science Curricula 2013: Curriculum Guidelines for Undergraduate Degree Programs in Computer Science (CS2013); http://www.acm.org/education/CS2013-finalreport.pdf. Accessed 2017 August 30.

[5] ACM et al., Computer Engineering Curricula 2016: Curriculum Guidelines for Undergraduate Degree Programs in Computer Engineering (CE2016); http://www.acm.org/binaries/content/assets/education/ce2016-finalreport.pdf. Accessed 2017 August 30.

[6] ACM et al., Computer Engineering 2004: Curriculum Guidelines for Undergraduate Degree Programs in Computer Engineering (CE2004); http://www.acm.org/education/education/curric_vols/CE-Final-Report.pdf. Accessed 2017 August 30.

[7] ACM et al., Information Technology Curricula 2017: Curriculum Guidelines for Undergraduate Degree Programs in Information Technology (IT2017);

[8] Exter, M. E. \& Turnage, N. M. Exploring experienced professionals' reflections on computing education. Transactions on Computing Education, 12 (3), 2012. 